\title{
DETERMINATION OF CHLORPYRIFOS IN LETTUCE (LACTUCA SATIVA L.) BY MICROWAVE- ASSISTED EXTRACTION COUPLED WITH HEADSPACE SINGLE DROP MICROEXTRACTION
}

\author{
NARUEPHON WATTHANAPHAPa, SURAPOL NATAKANKITKUL ${ }^{a}$, NUCHNART JONGLAEKHA ${ }^{{ }^{*}}$ \\ aFaculty of Pharmaceutical Sciences, Chiang Mai University, Thailand, bPlant Protection Center, Royal Project Foundation, Thailand \\ Email: yod414@gmail.com
}

Received: 30 Dec 2016 Revised and Accepted: 31 Mar 2017

\section{ABSTRACT}

Objective: The objective of this research was to improve the method of extracting pesticide residue from vegetable by using microwave-assisted extraction, headspace single drop microextraction (MAE-HS-SDME) and analysed by gas chromatograph-mass spectrometer (GC-MS)

Methods: Microwave-assisted extraction (MAE) coupled with headspace single drop microextraction (HS-SDME) was used for extraction of chlorpyrifos insecticide residues in lettuce. The optimum conditions for obtaining efficient extraction have been tried; kind and quantity of solvent, extraction time, microwave irradiation power, $\mathrm{pH}$ value and the amount of salt added in the sample followed the method of Plackett-Burman. Optimum conditions for efficient analysis were evaluated by using a central composite design (CCD) combined with a response surface methodology (RSM).

Results: The optimum extract conditions from CCD for the MAE-HS-SDME method were: using $1.5 \mu$ l of n-butyl acetate, 460 W of the microwave power, $4.5 \mathrm{~min}$ of the extraction time, no $\mathrm{pH}$ adjustment and no salt addition. Verification of the optimized experimental conditions showed that validation of the determination coefficient ranges from the concentrations of 0.01 to $0.10 \mathrm{mg} / \mathrm{l}$, equal to 0.999 ; the percentages of variation coefficient were ranges from 4.6 to $7.7 \%$; the recoveries ranges from 70.0 to $79.5 \%$; limit of detection was $0.003 \mathrm{mg} / \mathrm{kg}$ and limit of quantitation was $0.01 \mathrm{mg} / \mathrm{kg}$.

Conclusion: In this study, the MAE-HS-SDME method coupled with GC-MS was found most suitable for chlorpyrifos analysis. The results obtained from analyzing chlorpyrifos in lettuce samples indicated that this method is rapid, simple, sensitive, reducible cost and safety for the analyst and the environment.

\section{Keywords: Chlorpyrifos, Headspace single drop microextraction, Microwave-assisted extraction}

(C) 2017 The Authors. Published by Innovare Academic Sciences Pvt Ltd. This is an open access article under the CC BY license (http://creativecommons.org/licenses/by/4.0/) DOI: http://dx.doi.org/10.22159/ijpps.2017v9i5.16849

\section{INTRODUCTION}

Checking pesticide residue, in fresh agricultural produces routinely, at a large amount, needs a most appropriate method; taking short time, no toxic waste, less labor cost and no danger during extraction. In the previous work: liquid-liquid extraction (LLE) was used; gas chromatography (GC) and high-performance liquid chromatography (HPLC), were used for analysis. It was found that LLE has many disadvantages; requiring a large amount of expensive and hazardous organic solvents which leaving toxic waste.

Moreover, it takes time and intensive labor cost and it has interference from the sample matrix. So, the extraction and clean-up method were tried but still not good enough. Later, single drop microextraction (SDME) was adopted [1-4]; it provides an alternative technique which integrates sampling, extracting, concentrating and directly injecting into GC for analysis. This technique is simple, rapid, inexpensive, uses a trace amount of organic solvent and gives cleaner extract.

However, SDME has some disadvantages such as unstable drop, interference from the sample matrix and relatively low precision; therefore, headspace single drop micro extraction (HS-SDME) was chosen [5], to avoid such the problem. The microwave irradiation has been investigated and widely applied in accelerating sample extraction [6-8]. The highly efficient heating mechanism, the dipole rotation, and ionic condition of polar substances under microwave irradiation make the temperature rise up very quickly. So, the microwave heating is considerably potential to improve HS-SDME technique for analysis. The statistical and experimental methodology [9-13] on screening conditions for efficient SDME, developed by Plackett-Burman, and significant variations, were optimized by using a central composite design (CCD) combined with a response surface methodology. This study was aimed at using HS-SDME assisted with microwave irradiation to help to accelerate sample extraction coupled with GC-MS analysis.

\section{MATERIALS AND METHODS}

\section{Materials}

Head lettuce samples were randomly taken from the royal project's plant produce centre, Chiang Mai, Thailand. Chlorpyrifos (an organophosphate pesticide) was obtained from Dr. Ehrenstorfer (Augsburg, Germany). Acetone (HPLC grade: Merck Chemicals; Darmstadt, Germany) was used to dissolve chlorpyrifos for making the standard stock solution. Toluene, n-butyl acetate, ethyl acetate and 1-octanol of HPLC grade were obtained from Sigma-Aldrich (St. Louis, MO, USA). The de-ionized water of HPLC grade was obtained from Labscan (Dublin, Ireland). Hydrochloric acid, sodium hydroxide and sodium chloride (AR grade) were obtained from Merck (Darmstadt, Germany). GC-MS (Agilent Technologies model $6890 \mathrm{~N}$, USA) with a fused-silica capillary column (HP-5MS, $30 \mathrm{~m} \times 0.25 \mathrm{~mm}$ I.D., $0.25 \mu \mathrm{m}$ film thickness, J and $\mathrm{W}$ scientific, CA, USA) were used for analysis.

\section{Sample preparation}

Head lettuce was cut into small pieces and homogenized with a blender. $10 \mathrm{~g}$ of blended sample was put into $250 \mathrm{ml}$ flask and $20 \mu \mathrm{l}$ of $100 \mathrm{mg} / \mathrm{l}$ chlorpyrifos standard solution (for $0.2 \mathrm{mg} / \mathrm{kg}$ concentration) was added; followed by adding $20 \mathrm{ml}$ of the deionized water (to decrease viscosity of the solution); mixed well by shaking and left for $2 \mathrm{~h}$ before extraction.

\section{Chemicals and reagent preparation}

Chlorpyrifos was dissolved with acetone at $1,000 \mathrm{mg} / \mathrm{l}$ as a standard stock solution; it was diluted to $100 \mathrm{mg} / \mathrm{l}$ and $10 \mathrm{mg} / \mathrm{l}$ before use. A fresh working solution of the standard was prepared at required dilution with acetone. Both standard solution and working standards were stored at $-18^{\circ} \mathrm{C}$ in amber glass bottle with Teflonlined caps. 


\section{MAE-HS-SDME setting up}

The microwave used in this study was modified from the ordinary home microwave $(2,450 \mathrm{MHz}$, Electrolux, EMM2005, China) with an irradiation power range of $100-800 \mathrm{~W}$. The microwave has a whole ( $9.5 \mathrm{~cm}$ diameter) in the middle part of the basal surface where the round glass plate was placed over this hole. The magnetic stirrer (Whatman, HPMS, England), that placed under the microwave, was used for stirring the samples at $300 \mathrm{rpm}$, during extraction. The microwave has a perforated hole $(2.5 \mathrm{~cm}$ diameter $)$ at the center of the top surface; which connected to a Y-shaped glass tube $(25 \mathrm{~cm}$ length, I.D.: $2 \mathrm{~cm}$ ), one arm is connected to the glass condenser ( 30 $\mathrm{cm}$ length), and another arm is connected with a $250 \mathrm{ml}$ round shaped flask containing the sample, and a magnetic stirring bar is placed inside the microwave. The glass condenser and the circulating cool water system is connected to the external cold bath refrigerator with temperature control at $10^{\circ} \mathrm{C}$. In order to condense vapor (to avoid loss from volatilization): the temperature of the vapor formed in the headspace sampling zone must be controlled, to reduce the effective power of microwave irradiation from overheating inside the microwave. The MW-HS-SDME sampling system was attached above the $y$-shaped glass tube. The SDME device consists of a $10 \mu$ SGE syringe (Melbourne, Australia) with a bevel needle tip (length: $5.0 \mathrm{~cm}$, i.d. $0.047 \mathrm{~cm}$ ). For safety, the outer wall of the microwave at the interface between the microwave body and the perforated holes was wrapped with aluminum foil, to avoid leakage of microwave irradiation during the experiments. The microsyringe (typically contain acceptor solvent) was clamped above the Y-shaped glass tube and its needle was passed through the septa (11 mm, Agilent Technologies, USA). The plunger was depressed; the drop of the acceptor phase was suspended above the surface of sample phase to perform headspace, which exposed to the sample with a magnetic stirrer, and turned on MW power. The extract was then allowed to absorb into the acceptor droplet. After 1-5 min extraction, the acceptor phase was withdrawn into the microsyringe and then directly injected into the GC-MS system for analysis. The action process of MAE-HS-SDME system is shown in fig. 1.

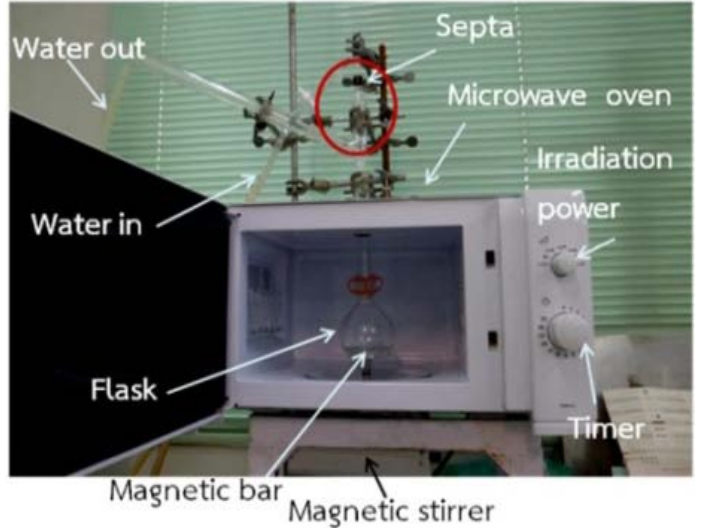

Fig. 1: Modified microwave as MAE-HS-SDME apparatus for rapid sample extraction procedure

\section{GC-MS determination}

Analysis of chlorpyrifos residue in lettuce was carried out by using GC-MS. Hydrogen (99.9995\% pure) was used as the carrier gas at a flow rate of $1.5 \mathrm{ml} / \mathrm{min}$. The injector temperature was maintained at $230{ }^{\circ} \mathrm{C}$ and operated in the splitless mode with a purge time of $0.75 \mathrm{~min}$. The column temperature program was initially set at 70 ${ }^{\circ} \mathrm{C}$ for $1 \mathrm{~min}$; then increased to $150{ }^{\circ} \mathrm{C}$ at the rate of $45^{\circ} \mathrm{C} / \mathrm{min}$, and finally increased to $200{ }^{\circ} \mathrm{C}$ at the rate of $5.4{ }^{\circ} \mathrm{C} / \mathrm{min}$ and held for 5 min. The mass spectrometer was performed on a 5975C inert XL MSD (Agilent Technologies, USA). The interface was kept at $280^{\circ} \mathrm{C}$ and the ionization mode was the electron ionization (EI) at $70 \mathrm{eV}$. With an ion source temperature at $230^{\circ} \mathrm{C}$. The characteristic fragment ions for chlorpyrifos compound $(\mathrm{m} / \mathrm{z}=197,199,258$, 260,314 and 316) were used for quantitative determination of selective ion monitoring (SIM) mode.

Table 1: Experimental factors and levels of the plackett-burman design

\begin{tabular}{|c|c|c|c|c|c|}
\hline \multirow{2}{*}{\multicolumn{3}{|c|}{ Factor }} & \multicolumn{3}{|l|}{ Level } \\
\hline & & & \multirow{2}{*}{$\begin{array}{l}\operatorname{Low}(\mathbf{- 1}) \\
1\end{array}$} & \multicolumn{2}{|l|}{ High (+1) } \\
\hline \multicolumn{3}{|c|}{ Drop volume $(\mu \mathrm{l})$} & & \multicolumn{2}{|l|}{2} \\
\hline \multicolumn{3}{|c|}{ Extraction time (min) } & 1 & \multicolumn{2}{|l|}{4} \\
\hline \multicolumn{3}{|c|}{ Microwave power $(\mathrm{W})$} & 200 & \multicolumn{2}{|l|}{450} \\
\hline \multicolumn{3}{|c|}{ Ionic strength $(\mathrm{NaCl} ; \% \mathrm{w} / \mathrm{v})$ concentration; \% w/v) } & 0 & \multicolumn{2}{|l|}{20} \\
\hline \multicolumn{3}{|c|}{$\mathrm{pH}$} & 4 & \multicolumn{2}{|l|}{7} \\
\hline Run & Drop volume & Extraction time & Microwave power & Ionic strength & pH \\
\hline 1 & +1 & -1 & +1 & -1 & -1 \\
\hline 2 & +1 & +1 & -1 & +1 & -1 \\
\hline 3 & -1 & +1 & +1 & -1 & +1 \\
\hline 4 & +1 & -1 & +1 & +1 & -1 \\
\hline 5 & +1 & +1 & -1 & +1 & +1 \\
\hline 6 & +1 & +1 & +1 & -1 & +1 \\
\hline 7 & -1 & +1 & +1 & +1 & -1 \\
\hline 8 & -1 & -1 & +1 & +1 & +1 \\
\hline 9 & -1 & -1 & -1 & +1 & +1 \\
\hline 10 & +1 & -1 & -1 & -1 & +1 \\
\hline 11 & -1 & +1 & -1 & -1 & -1 \\
\hline 12 & -1 & -1 & -1 & -1 & -1 \\
\hline
\end{tabular}

In the MAE-HS-SDME procedure: a $10 \mu \mathrm{l}$ microsyringe was used to measure and introduce the micro drop of solvent $(1.5 \mu \mathrm{l}$ of $\mathrm{n}$ butyl acetate) into the headspace above the sample flask. The needle of the microsyringe was inserted through the septum for sampling the insecticide vapor, formed in the headspace sampling zone of the extracts, under fixed stirring rate 300 $\mathrm{rpm}$ ) with magnetic stirring bar.

The microwave irradiation power $(460 \mathrm{~W})$ was turned on; then depressed the microsyringe plunger to expose the solvent drop; the vapor of the sample occurred; then transferred the extract from the vapor phase to the solvent drop. After the extraction was finished ( $4.5 \mathrm{~min}$ ), the solvent drop was drawn back into the syringe and the needle was removed from the headspace sampling zone; then immediately injected into the gas chromatograph with a mass spectrometer (total run time $=12.5 \mathrm{~min}$ ).

\section{Selection of organic solvent}

To achieve high extraction efficiency in MAE-HS-SDME procedure: several solvents with different polarity and viscosity, were screened according to their characteristics on the extraction efficiency, and appropriate for injection in the gas chromatograph. In this study, toluene, n-butyl acetate, ethyl acetate and 1-octanol were tested and 
examined from the triplicate extraction of $10 \mathrm{~g}$ of lettuce sample; spiked with the $0.2 \mathrm{mg} / \mathrm{kg}$ of chlorpyrifos; then extracted with $2 \mu \mathrm{l}$ of the organic solvent drop, at a stirring rate of $300 \mathrm{rpm}$, under 450 $\mathrm{W}$ of microwave irradiation for $4 \mathrm{~min}$.

\section{Screening design}

For screening purpose, when a high number of variations was involved, the reduce Plackett-Burman design was usually employed. The aim of this design was to identify those variations presenting the greatest influence (significant) on the selected response, by calculation of the main effect. Each variation of the Plackett-Burman design from running 12 experiments is shown in table 1 ; where two levels are considered to be preliminary test experiment. A $t$-test used for evaluation of the data showed a statistically significant difference at $95 \%$ confidence level.

\section{Optimization design}

The next study was concerned with optimizing the values of the significant variation, in order to achieve the best response (peak area). A response surface methodology (RSM) was applied followed by a central composite design (CCD), to assess the influence of the three main factors on the microwave-microextraction process, in order to obtain the optimal working conditions. The CCD consists of the points of factorial design $\left(2^{\mathrm{k}}\right)$ augmented with $(2 \mathrm{k})$ star points; where $\mathrm{k}$ is the number of variables to be optimized, and with a central point, which can be run at $\mathrm{n}$ time.
The axial distances (star points) are located at $\pm \alpha$ from the centre of the experiment domain. An $\alpha$ was selected with a value of 1.0 in order to establish the face centred design (FCCD). The runs at the centre of the experiment (n) were performed for six times. Therefore, in overall 20 tests matrix of FCCD design was involved. In this study, the three significant variables; which influenced considerably were: drop volume, extraction time, and microwave power. The low (-1), central (0), and high (+1) levels of these variables, as well as the location of their star points, are also indicated in table 2 .

\section{Validation of MAE-HS-SDME}

The MAE-HS-SDME was used to verify the applicability of the proposed method for quantitative determination of chlorpyrifos, using GC-MS by adding chlorpyrifos standard solution to the lettuce sample. The validation procedure was based on the Codex Guideline CAC/GL 40-1993, Rev.1-2003 [14]. Quality parameters including accuracy, precision, limit of detection (LOD), limit of quantitation (LOQ), linear range, as well as specificity, were investigated.

\section{Comparison of methods}

The proposed method was applied to the determination of spiking chlorpyrifos pesticide standard samples at two concentrations of 0.02 and $0.2 \mathrm{mg} / \mathrm{kg}$ with ten replicates. The results obtained were statistically compared with official standard method [15-16] by applying the paired T-test with means for accuracy and F-values for precision.

Table 2: Experimental factors and levels of the face-centered central composite design (FCCD) at star point, $\alpha=1$

\begin{tabular}{|c|c|c|c|}
\hline \multirow[t]{2}{*}{ Factor } & \multicolumn{3}{|l|}{ Level } \\
\hline & Low $(-1)$ & Central (0) & High (+1) \\
\hline Drop volume $(\mu \mathrm{l})$ & 1 & 1.5 & 2 \\
\hline Extraction time (min) & 2 & 4 & 6 \\
\hline Microwave power (W) & 300 & 450 & 600 \\
\hline Run & Drop volume & Extraction time & Microwave power \\
\hline 1 & -1 & -1 & -1 \\
\hline 2 & +1 & -1 & -1 \\
\hline 3 & -1 & +1 & -1 \\
\hline 4 & 1 & +1 & -1 \\
\hline 5 & -1 & -1 & +1 \\
\hline 6 & +1 & -1 & +1 \\
\hline 7 & -1 & +1 & +1 \\
\hline 8 & +1 & +1 & +1 \\
\hline 9 & -1 & 0 & 0 \\
\hline 10 & +1 & 0 & 0 \\
\hline 11 & 0 & -1 & 0 \\
\hline 12 & 0 & 1 & 0 \\
\hline 13 & 0 & 0 & -1 \\
\hline 14 & 0 & 0 & +1 \\
\hline 15 & 0 & 0 & 0 \\
\hline 16 & 0 & 0 & 0 \\
\hline 17 & 0 & 0 & 0 \\
\hline 18 & 0 & 0 & 0 \\
\hline 19 & 0 & 0 & 0 \\
\hline 20 & 0 & 0 & 0 \\
\hline
\end{tabular}

\section{Analytical applications}

In order to examining the suitability of the proposed method, the insecticide chlorpyrifos at two concentrations of 0.02 and $0.2 \mathrm{mg} / \mathrm{kg}$ was used for the test. Five replicates of different types of vegetable samples including lettuce, cabbage, Chinese kale, sweet pepper, and tomato, were prepared and analyzed by MAE-HS-SDME. The precision and accuracy of the method were further compared statistically, using ANOVA at 95\% confidence level.

\section{RESULTS AND DISCUSSION}

\section{Selection of organic solvent}

Ethyl acetate, toluene, and 1-octanol are the problem of unstable drop due to high volatilization occurred during the extraction procedure; ethyl acetate disappeared from the needle tip. The drawn-back volume of the toluene and 1-octanol was less than $1 \mu$; n-butyl acetate which was less volatile and gave the best extraction results (table 3 and fig. 2); which shows the effect of using MAE-HSSDME extraction on detection peak area of the chloryrifos (relative to extraction efficiency). Thus, n-butyl acetate was chosen to be the extraction solvent for MAE-HS-SDME in the next optimization procedure.

\section{Screening design}

The variable extraction conditions of the MAE-HS-SDME in correspondence with peak area, from a Plackett-Burman design, for chlorpyrifos, is shown in table 4; the plotting main effect of peak area for chlorpyrifos after MAE-HS-SDME extraction is shown in fig. 3. The results were visualized by using the main effect Pareto chart (fig. 4). 
According to the results: microwave irradiation power, extraction time, and drop volume are important in MAE-HS-SDME. The microwave irradiation power is the most significant factor, displaying a positive effect; the signal intensity of chlorpyrifos was increased with the increase of microwave power; which reinforces the assertion of a previous report [17]. The extraction efficiency: due to the vaporization rate of the extract from the sample under the sufficient microwave irradiation power, can accelerate the volatilization of the extract. At higher microwave power: the extracted vapor in the headspace was increased, which would help much more extract evaporate from liquid or solid vegetable matrix to the headspace and extracted by suspended solvent drop.

Table 3: The effect of extraction solvent on the peak areas of the chlorpyrifos

\begin{tabular}{ll}
\hline Solvent & Peak area (average) \\
\hline n-Butyl acetate & 318504 \\
Ethyl acetate & Not Available ${ }^{\mathrm{a}}$ \\
Toluene & Not Suitable ${ }^{\mathrm{b}}$ \\
1-Octanol & Not Suitable $^{\mathrm{b}}$ \\
\hline
\end{tabular}

aCould not inject to GC/MS inlet, bNot suitable for analysis

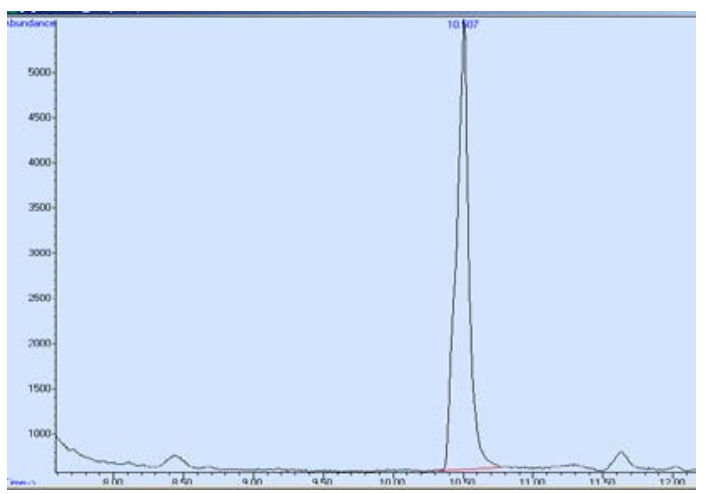

Fig. 2: GC-MS chromatogram of the chlorpyrifos after MAE-HSSDME extraction using n-butyl acetate as the extraction solvent

Extraction time is the next highly significant variation, showing a positive effect; result showed that the peak areas increased with increasing extraction time, which is agreeable to a previous report [18]. The extraction efficiency depends on the extraction time; due to an equilibrium process which the extract had a partition between the extracted vapor and the headspace extraction solvent drop.

Drop volume is the next significant variable, which exhibits a negative effect. Results showed that the peak areas decreased with increasing drop volume; which is agreeable to a previous report [19]. In general, an increase in the signal peak area is expected on increasing drop volume. However, the bigger organic solvent drop is required for extending equilibration time because mass transfer inside the drop is by diffusion alone, representing a slower extraction procedure.
Ionic strength (salt addition) also appeared to have a negative significant effect. The result showed that the analytical response of chlorpyrifos was decreased with the increase of $\mathrm{NaCl}$ concentration; the result is agreeable to previous reports [1719]. The addition of $\mathrm{NaCl}$ in a sample solution may have an impact on the extraction because it increases the ionic strange of the solution and decreases the water solubility of the extract and consequently to enhance the extraction yield, due to the saltingout effect.

However, most liquid phase micro extraction procedures reported in the current literature indicated that ionic strength had no effect or sometimes could decrease extraction efficiency of the extract and usually most methods do not adding salt in the sample solution. The presence of salt may have a secondary effect by altering the physical properties of diffusion film; which cause reducing the diffusion rate of the extract into the solvent drop. In addition, this variation had a small negative effect on the extraction. So, it was decided not to add salt in the subsequent experiments.

According to the Pareto chart, $\mathrm{pH}$ exhibited a positive little significant effect. The ionisation form of the extracts changed with the modification of $\mathrm{pH}$, affecting their water solubility and extractability. In this study, the effect of $\mathrm{pH}$ was investigated by varying the $\mathrm{pH}$ from 4.0 to 7.0 only. It has been known that decomposition of organophosphate pesticides, causes reduction of extraction efficiency at high $\mathrm{pH}$ levels. Therefore, the original unadjusted pH 7 sample was chosen for further experiments.

Relying on the obtained results and the discussions above, $\mathrm{NaCl}$ and $\mathrm{pH}$ were not included in further studies. So, the factors chosen to include in the following optimization (CCD) were drop volume, extraction time and microwave power. The other parameters used were: $300 \mathrm{rpm}$ for stirring speed at the original $\mathrm{pH}$; and no salt added.

Table 4: Variable extraction conditions of the MAE-HS-SDME in correspondence with peak area from a Plackett-Burman design for chlorpyrifos

\begin{tabular}{|c|c|c|c|c|c|c|}
\hline Run & $\begin{array}{l}\text { Drop volume } \\
(\mu \mathrm{l})\end{array}$ & $\begin{array}{l}\text { Extraction time } \\
\text { (min) }\end{array}$ & $\begin{array}{l}\text { Microwave power power } \\
\text { (W) }\end{array}$ & $\begin{array}{l}\text { Ionic strength } \\
(\% \mathrm{NaCl} w / v)\end{array}$ & pH & Peak area \\
\hline 1 & 2 & 1 & 450 & 0 & 4 & 147744 \\
\hline 2 & 2 & 4 & 200 & 20 & 4 & 93912 \\
\hline 3 & 1 & 4 & 450 & 0 & 7 & 338630 \\
\hline 4 & 2 & 1 & 450 & 20 & 4 & 119414 \\
\hline 5 & 2 & 4 & 200 & 20 & 7 & 107754 \\
\hline 6 & 2 & 4 & 450 & 0 & 7 & 267964 \\
\hline 7 & 1 & 4 & 450 & 20 & 4 & 291171 \\
\hline 8 & 1 & 1 & 450 & 20 & 7 & 186995 \\
\hline 9 & 1 & 1 & 200 & 20 & 7 & 42561 \\
\hline 10 & 2 & 1 & 200 & 0 & 7 & 7813 \\
\hline 11 & 1 & 4 & 200 & 0 & 4 & 165645 \\
\hline 12 & 1 & 1 & 200 & 0 & 4 & 48902 \\
\hline
\end{tabular}




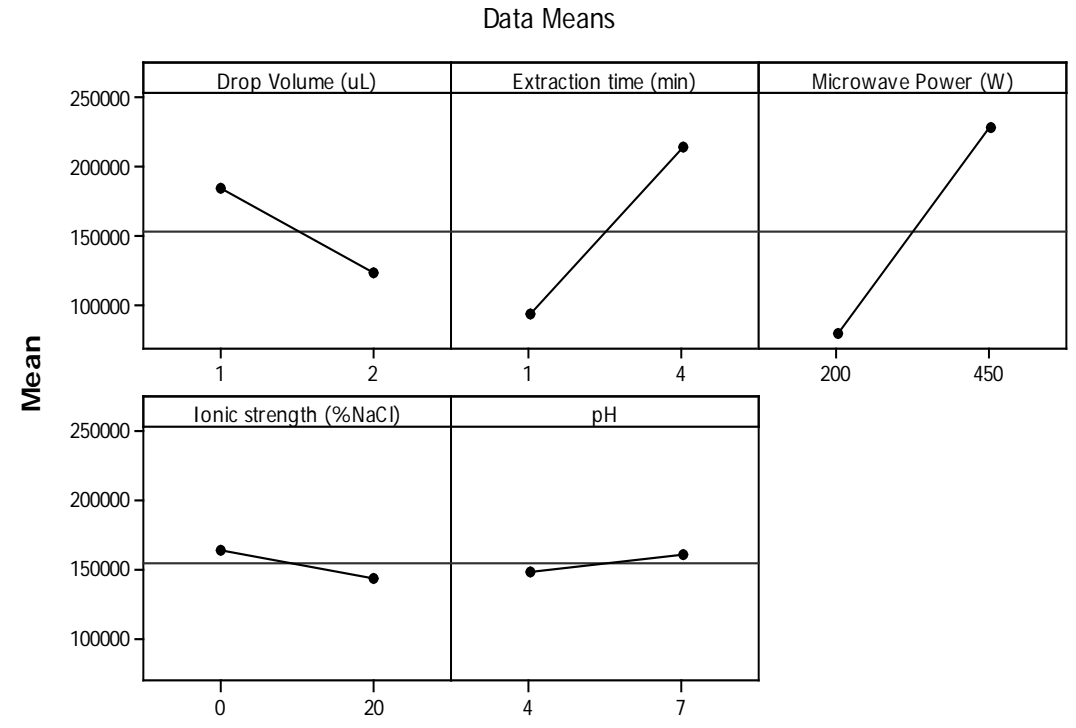

Fig. 3: Main effect of peak area for chlorpyrifos analysis, using MAE-HS-SDME

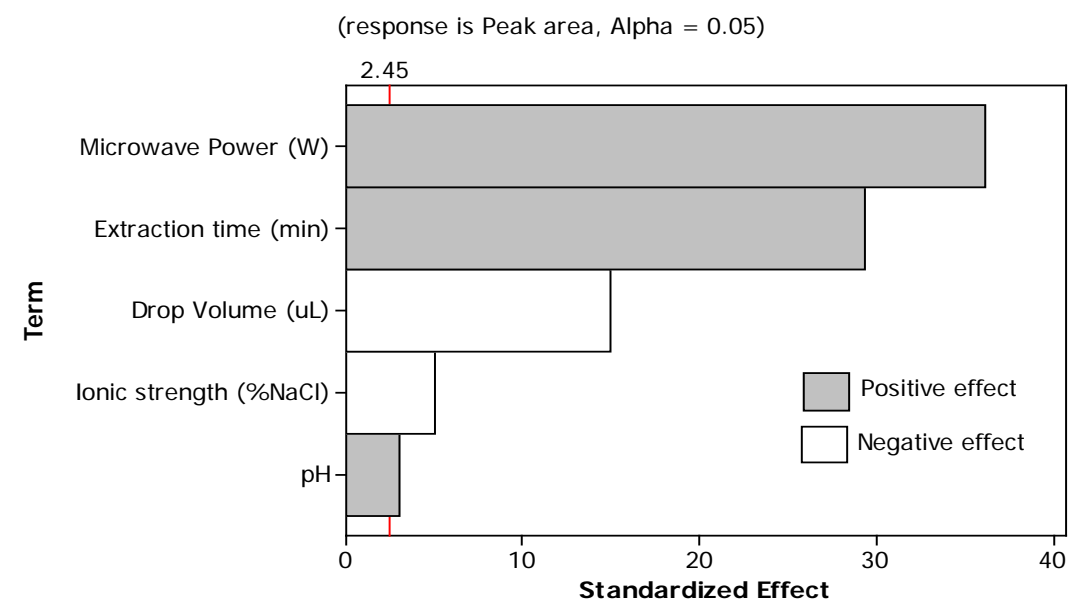

Fig. 4: Pareto chart of the main effect obtained from a placked-burman design, for chlorpyrifos extraction, using mae-hs-sdme

Table 5: The MAE-HS-SDME optimization corresponds with peak area of chlorpyrifos by the face-centered central composite design (FCCD) at star point, $\alpha=1$

\begin{tabular}{|c|c|c|c|c|}
\hline Run & Drop volume $(\mu \mathrm{l})$ & Extraction time (min) & Microwave power (W) & Peak area \\
\hline 1 & 1 & 2 & 300 & 11440 \\
\hline 2 & 2 & 2 & 300 & 21855 \\
\hline 3 & 1 & 6 & 300 & 126838 \\
\hline 4 & 2 & 6 & 300 & 137938 \\
\hline 5 & 1 & 2 & 600 & 80342 \\
\hline 6 & 2 & 2 & 600 & 91954 \\
\hline 7 & 1 & 6 & 600 & 197140 \\
\hline 8 & 2 & 6 & 600 & 202732 \\
\hline 9 & 1 & 4 & 450 & 340028 \\
\hline 10 & 2 & 4 & 450 & 349373 \\
\hline 11 & 1.5 & 2 & 450 & 212239 \\
\hline 12 & 1.5 & 6 & 450 & 318131 \\
\hline 13 & 1.5 & 4 & 300 & 185623 \\
\hline 14 & 1.5 & 4 & 600 & 248364 \\
\hline 15 & 1.5 & 4 & 450 & 376312 \\
\hline 16 & 1.5 & 4 & 450 & 384879 \\
\hline 17 & 1.5 & 4 & 450 & 345252 \\
\hline 18 & 1.5 & 4 & 450 & 348950 \\
\hline 19 & 1.5 & 4 & 450 & 363758 \\
\hline 20 & 1.5 & 4 & 450 & 360979 \\
\hline
\end{tabular}



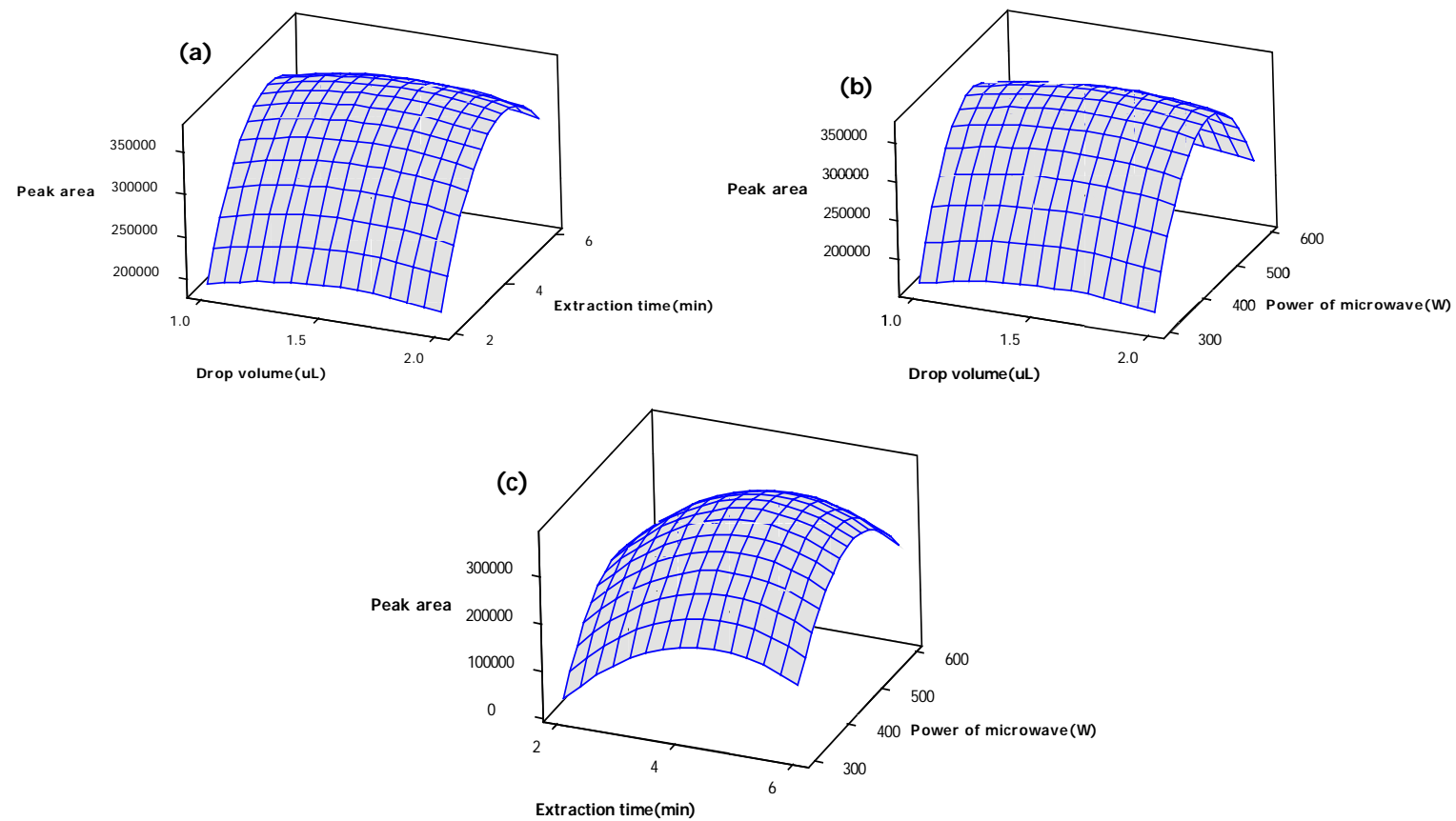

Fig. 5: Response surface for chlorpyrifos peak area, using the central composite design obtained from graph plotting: (a) drop volume vs. extraction time (power of microwave: $450 \mathrm{~W}$ ); (b) drop volume vs. power of microwave (extraction time: 4 min); and (c) extraction time vs. power of microwave (drop volume: $1.5 \mu \mathrm{l}$ )

\section{Optimization design}

The results from optimization study are summarized in table 5 . Furthermore: plotting graph of the GC-MS response, as a function of The results of this optimization study indicated that response surface model was developed by considering the significant responses in the term of coded value equation as shown below:

$\mathrm{Y}=-1687075+201793 \mathrm{X}_{1}+220057 \mathrm{X}_{2}+5971.06 \mathrm{X}_{3}-62093.1 \mathrm{X}_{1}{ }^{2}-23759$. $7 \mathrm{X}_{2}{ }^{2}-6.36579 \mathrm{X}_{3}{ }^{2}-666.875 \mathrm{X}_{1} \mathrm{X}_{2}-7.18500 \mathrm{X}_{1} \mathrm{X}_{3}-1.62708 \mathrm{X}_{2} \mathrm{X}_{3}$

Where $Y$ is the peak area of chlorpyrifos, $X_{1}$ is drop volume $(\mu \mathrm{l}), X_{2}$ is extraction time ( $\mathrm{min}$ ) and $\mathrm{X}_{3}$ is a power of microwave (W). For the quadratic models, the optimization condition could be calculated.

It can be concluded that the optimal extraction conditions for MAEHS-SDME obtained from the software are as follows: $1.5 \mu \mathrm{ln}$-buthyl all the factors controlling the extraction process, enabled to visualize the separation effects of the paired factors. The response surface charts are shown in fig. 5.

acetate as the extraction solvent, the extraction time at $4 \mathrm{~min}$; the microwave irradiation power at $460 \mathrm{~W}$; the stirring rate at $300 \mathrm{rpm}$; without $\mathrm{pH}$ adjustment and no salt addition.

\section{Validation of MAE-HS-SDME}

The results of validation method are summarized in table 6. A calibration curve was performed by spiking blank lettuce samples with chlorpyrifos over the concentration ranges from 0.01 to $1.0 \mathrm{mg} / \mathrm{kg}$.

The calibration curve shows a high level of linearity for the extracts with the coefficients of determination $\left(\mathrm{r}^{2}\right)$ at 0.995.

Table 6: Method validation parameters for determination of chlorpyrifos in lettuce using MAE-HS-SDME method

\begin{tabular}{lllll}
\hline $\mathbf{r}^{\mathbf{2 a}}$ & $\mathbf{\% R}^{\mathbf{b}}$ & $\mathbf{\% C V}^{\mathbf{c}}$ & $\left.\mathbf{L O D}^{\mathbf{d}} \mathbf{( m g} / \mathbf{k g}\right)$ & $\mathbf{L O Q}^{\mathbf{e}} \mathbf{( m g / k g )}$ \\
\hline 0.999 & $70.0-79.5$ & $4.6-7.7$ & 0.003 & 0.01 \\
\hline
\end{tabular}

aDetermination coefficient, $\mathrm{r}^{2}$ linear ranges of $0.01-1.0 \mathrm{mg} / \mathrm{kg}$, ${ }^{\mathrm{b}}$ Relative recovery, accuracy was investigated at $0.02-1.0 \mathrm{mg}-\mathrm{kg}(\mathrm{n}=10)$, ${ }^{\mathrm{c} C o e f f i c i e n t}$ of variation, repeatability was investigated at $0.02-0.2 \mathrm{mg}-\mathrm{kg}(\mathrm{n}=10)$, dLimit of detection (LOD) was calculated at the three signal-to-noise ratio $(\mathrm{S} / \mathrm{N} \geq 3)$, eLimit of quantification ( $\mathrm{LOQ})$ was calculated at the ten signal-to-noise ratio $(\mathrm{S} / \mathrm{N} \geq 10)$

The recovery of the MAE-HS-SDME method was determined by spiking samples with chlorpyrifos pesticide standards at concentrations of $0.2,0.5$, and $1.0 \mathrm{mg} / \mathrm{kg}$. The spiked, and control samples were analyzed by this proposed method in five replicates and the average recovery percentage was calculated. In order to have sufficiently accurate results for the analysis of pesticide residue in vegetable, the recovery obtained must be in the range of 70 to $120 \%$ [14]. The proposed method was proved to be accurate, as the achievement of recovery was in the range of 70.0 to $79.5 \%$.

The precision of this proposed method using repeatability was prepared and analyzed in ten replicates within the same day (intraday precision) and on other days (inter-day precision); which evaluated through the percentage coefficient of variation $(\% \mathrm{CV})$; which determined by spiking samples with chlorpyrifos pesticide standards at two levels of 0.02 and $0.2 \mathrm{mg} / \mathrm{kg}$. The calculated values of $\% \mathrm{CV}$ were in the range of 4.6 to $7.7 \%$; thus indicating that the proposed method is precise.

For determining the limit of detection (LOD) and limit of quantification (LOQ) value of this proposed method: the LOD/10Q values were predicted from the signal to noise $(\mathrm{S} / \mathrm{N})$ ratio data, based on a S/N ratio of 3:1 for the LOD and 10:1 with acceptable accuracy and precision for the LOQ.

The LOD/IOQ evaluation was prepared at predicted concentration levels and precise by analyzing ten times, as shown in table 6 .

The LOD and LOQ value found were at $0.003 \mathrm{mg} / \mathrm{kg}$ and $0.01 \mathrm{mg} / \mathrm{kg}$, respectively; comparable to those reported elsewhere [20-22] which confirm the high sensitivity of the method. In fact, the proposed method is capable of detecting and quantifying chlorpyrifos 
concentrations at below $0.05 \mathrm{mg} / \mathrm{kg}$, according to the $\mathrm{EU}$ maximum residue limits.

The linearity of this method was determined by analysis of spiking samples; using the proposed method with three replicates of a series of chlorpyrifos at concentrations of $0.003,0.01,0.02,0.05,0.1,0.2,0.4$, 0.8 and $1.0 \mathrm{mg} / \mathrm{kg}$. The statistical parameters correlation coefficient values were calculated by linear regression analysis. The linear relationship between the peak area and the spiked quantity of chlorpyrifos was in good agreement with a coefficient of determination $\left(\mathrm{r}^{2}\right)$ at 0.999

\section{Comparison of methods}

The results obtained were statistically compared with official standard method (AOAC), by applying the paired T-test with means for accuracy and F-values for precision; the result is shown in table 7. The calculated $\mathrm{t}$ and $\mathrm{F}$ values at $95 \%$ confidence level did not exceed the tabulated value of $t=2.26$ and 3.18 respectively; with nine degrees of freedom. The results indicated that there is no difference between the proposed method and the official method [15-16] with respect to accuracy and precision at $95 \%$ confidence level.

Table 7: Determination of spiked chlorpyrifos in lettuce sample by the MAE-HS-SDME method to compare with QuEChERS method

\begin{tabular}{|c|c|c|c|c|c|c|}
\hline \multirow{3}{*}{$\begin{array}{l}\text { Concentration } \\
\text { (mg/kg) }\end{array}$} & \multicolumn{2}{|c|}{ Amount found ${ }^{\mathrm{a}} \pm \mathrm{SD}$} & \multicolumn{4}{|c|}{ Percentage recovery and variation } \\
\hline & \multirow{2}{*}{$\begin{array}{l}\text { MAE-HS-SDME } \\
(\mathrm{mg} / \mathrm{kg})\end{array}$} & \multirow{2}{*}{$\begin{array}{l}\text { QuEChERS } \\
\text { (mg/kg) }\end{array}$} & \multicolumn{2}{|c|}{ MAE-HS-SDME } & \multicolumn{2}{|c|}{ QuEChERS } \\
\hline & & & $\% \mathbf{R}^{\mathbf{b}}$ & $\% \mathrm{CV}^{\mathrm{c}}$ & $\% \mathbf{R}^{\mathbf{b}}$ & $\% \mathrm{CV}^{\mathrm{c}}$ \\
\hline 0.02 & $\begin{array}{l}0.140 \pm 0.013 \\
t=1.12 \\
\mathrm{~F}=2.13\end{array}$ & $0.147 \pm 0.009$ & 70.0 & 9.4 & 73.6 & 6.1 \\
\hline 0.2 & $\begin{array}{l}0.0145 \pm 0.002 \\
t=2.18 \\
\mathrm{~F}=2.00\end{array}$ & $0.0152 \pm 0.001$ & 72.5 & 5.0 & 75.8 & 3.4 \\
\hline
\end{tabular}

aAverage of 10 replications, the paired $t$-test and F-test value refer to the comparison of the proposed method with the referent method. Theoretical values at $95 \%$ confidence level, $t=2.26, \mathrm{~F}=3.18$, bRelative recovery $(\mathrm{n}=10)$, 'Coefficient of variation $(\mathrm{n}=10)$

Table 8: Comparison of relative response (\% $\mathrm{R} \pm \mathrm{CV})$ of chlorpyrifos in spiked different vegetable samples by the optimized MAE-HS-SDME method

\begin{tabular}{|c|c|c|c|c|c|}
\hline \multirow[t]{2}{*}{ Concentration (mg/kg) } & \multicolumn{4}{|c|}{ Percentage recovery and variation a $(\% \mathrm{R} \pm \mathrm{CV})$} & \multirow[t]{2}{*}{ ANOVA $^{\mathrm{b}}$} \\
\hline & Lettuce & Cabbage & Bell pepper & Tomato & \\
\hline 0.02 & $73.2 \pm 6.1$ & $73.6 \pm 6.9$ & $70.8 \pm 8.9$ & $69.7 \pm 7.6$ & 0.617 \\
\hline 0.2 & $74.6 \pm 8.8$ & $73.6 \pm 7.4$ & $81.2 \pm 6.7$ & $79.6 \pm 9.0$ & 0.428 \\
\hline
\end{tabular}

aAverage percentage recovery \pm coefficient of variation $(n=5)$ of chlorpyrifos after MAE-HS-SDME extraction of spiked vegetable extracts, $\mathbf{b}$ Analysis of variance performed among the relative recovery of chlorpyrifos in a spiked sample by the MAE-HS-SDME method (n=5). Significant difference at $95 \%(\mathrm{p}<0.05)$.

\section{Analytical applications}

In order to examine the suitability of the proposed method: the result is shown in table 8 . The recoveries for the spiked sample were ranges from 69.7 to $81.2 \%$. However, no statistical differences were found among them. This is considered sufficiently accurate for the analysis of pesticide residue in vegetable, which indicated that the proposed method is feasible for the determination of chlorpyrifos in vegetable samples.

\section{CONCLUSION}

In this study, the MAE-HS-SDME method coupled with GC-MS was developed to analyse chlorpyrifos residue in the lettuce samples. This method was optimized with various parameters affecting the extraction efficiency by using the method of Plackett-Burman with a central composite design (CCD) together with a response surface methodology. The optimum extract conditions were: using $1.5 \mu \mathrm{l}$ of n-butyl acetate as micro drop solvent, $460 \mathrm{~W}$ of the microwave irradiation, 4.5 min of the extraction time, without $\mathrm{pH}$ adjustment and no salt addition. Verification of the optimized experimental conditions showed that validations have also evaluated the coefficients of determination $\left(\mathrm{r}^{2}\right)$ ranges from 0.998 to 0.999 at concentrations of $0.01-0.10 \mathrm{mg} / \mathrm{l}$. The percentage of coefficient of variation $(\% \mathrm{CV})$ ranges from 4.6 to $7.7 \%$; the recovery ranges from 70.0 to $79.5 \%$; limit of detection (LOD) was at $0.003 \mathrm{mg} / \mathrm{kg}$ and limit of quantitation (LOQ) was at $0.01 \mathrm{mg} / \mathrm{kg}$. From the results of the applicable test for chlorpyrifos determination in the lettuce and other vegetable samples: the present method is found to be rapid, simple, sensitive, reducible cost and environment-friendly method.

\section{CONFLICTS OF INTERESTS}

All authors have none to declare

\section{REFERENCES}

1. Jeannot MA, Cantwell FF. Solvent microextraction into a single drop. Anal Chem 1996;68:2236-40.

2. Zhang M, Huang J, Wei C, Yu B, Yang X, Chen X. Mixed liquids for single-drop microextraction of organochlorine pesticides in vegetables. Talanta 2008;74:599-604.

3. Amvrazi EG, Tsiropoulos NG. Chemometric study and optimization of extraction parameters in single-drop. J Chromatogr A 2009;1216:7630-8.

4. Amvrazi EG, Tsiropoulos NG. Application of single-drop microextraction coupled with gas chromatography for the determination of multiclass pesticides in vegetables with nitrogen phosphorus and electron capture detection. J Chromatogr A 2009;1216:2789-97.

5. Xiao Q, Hu B, He M. Speciation of butyltin compounds in environmental and biological samples using headspace single drop microextraction coupled with gas chromatographyinductively coupled plasma mass spectrometry. J Chromatogr A 2008;1211:135-41.

6. Abdelmohsen MM, Nazif NM, Seif el Nasr MM. Microwaveassisted extraction of bio-active compounds (phenolics and alkamides) from Echinacea purpurea. Int J Pharm Pharm Sci 2014;6:265-8.

7. Kormin F, Khan M, Chandra AI. Microwave assisted extraction; Phytochemical evaluation of Malaysian palm oil trunk epiphytes ferns. Int J Pharm Pharm Sci 2016;8:174-80.

8. Pramanik T, Majia P. Microwave assisted green synthesis of pharmaceutically important dihydropyrimidinones in fruit juice medium. Int J Pharm Pharm Sci 2015;7:376-9.

9. Rebbapragada D, Kalyanaraman R. Statistical optimization of the medium of components by Plackett-Burman design and response surface methodology for enhanced antioxidant 
activity by Xylaria feejeensis HMJAU22039. Int J Pharm Pharm Sci 2016;8:159-64.

10. Kuchekar SB, Mohite KS. Design and evaluation of extended release ranolazine liauisoloid tablets using placket-burman screening design. Asian J Pharm Clin Res 2015;8:292-300.

11. Sumithra S. Application of quality by design (CCD technique) for simultaneous estimation of cefixime and ofloxacin by HPTLC methods. Int J Pharm Pharm Sci 2016;8:200-8.

12. Kumar GN, Kuma S, Vimalan S, Prakash P, Nandagopal S, Kumar RB. Optimization of growth promoters on Desmodium gangeticum (L) DC using RSM-CCD and its antioxidants activity. Int J Pharm Pharm Sci 2014;6:503-7.

13. Satishkumar PJ, Singh PP, Javeer S, Purnima D. Use of PlacketBurman statistical design to study the effect of formulation variables on the release of drug from hot melt sustained release extrudates. AAPS PharmSciTech 2010;11:936-44.

14. Codex Alimentarius Commission. Guideline on good laboratory practice in pesticide residue analysis CAC/GL 401993; 2003. p. 1-36.

15. Lehotay SJ. Determination of pesticides residues in food by acetonitrile extraction and partitioning with magnesium sulfate: Collaborative study. J AOAC Int 2007:90:485-517.

16. EN 15662:2008 standard, foods of plant origin determination of pesticide residues using GC-MS and/or LC-MS/MS following acetonitrile extraction/partitioning and clean-up by dispersive SPE-QuEChERS-method; 2008.

17. Cortada C, Vidal L, Tejada S, Romo A, Canals A. Determination of organochlorine pesticides in complex matrices by singledrop microextraction coupled to gas chromatography-mass spectrometry. Anal Chim Acta 2009;638:29-35.
18. Lorena Vidal, Domini CE, Gran N, Psillakis E, Canals A Microwave-assisted headspace single-drop microextraction of chlorobenzenes from water samples. Anal Chim Acta 2007;592:5-15.

19. Kumar PV, Jen JF. Rapid determination of dichlorodiphenyltrichloroethane and its main metabolites in aqueous samples by one-step microwave-assisted headspace controlled-temperature liquid-phase microextraction and gas chromatography with electron capture detection. Chemosphere 2011;83:200-7.

20. Pinheiro AS, de Andradea JB. Development, validation and application of an SDME/GC-FID methodology for the multi residue determination of organophosphate and pyrethroid pesticides in water. Talanta 2009;79:1354-9.

21. Pinheiro AS, Rocha GO, de Andrade JB. A SDME/GC-MS methodology for determination of organophosphate and pyrethroid pesticides in water. Microchem J 2011;99:303-8.

22. Garbi A, Sakkas V, Fiamegos YC, Stalika CD, Albanis T. Sensitive determination of pesticides residues in wine samples with the aid of single-drop microextraction and response surface methodology. Talanta 2010;82:1286-91.

\section{How to cite this article}

- $\quad$ Naruephon Watthanaphap, Surapol Natakankitkul, Nuchnart Jonglaekha. Determination of chlorpyrifos in lettuce (Lactuca sativa L.) by microwave-assisted extraction coupled with headspace single drop microextraction. Int J Pharm Pharm Sci 2017;9(5):248-255. 